\section{Benefits and dangers of genetic tests}

Sir - The potential for causing mischief by carrying out genetic analysis on an estimated 283 million archived tissue samples has become the focus of the US National Bioethics Advisory Commission.

French-Canadians living in Maine or Japanese-Americans living in California might learn about increased susceptibility to certain genetic traits, including disease predispositions, without any member from these groups consenting to participate in such analyses. Similarly, tribal customs might be disregarded in handling surgical or post-mortem remains. This had led to proposals for "community consultation".

In a News story, "'Group debate' urged for gene studies"2, Meredith Wadman cited a study of increased heritable susceptibility to colon cancer among Ashkenazi Jews as the trigger for this recommendation ${ }^{3}$. I should like to emphasize that, rather than ignoring the Ashkenazi Jewish community, this study has been a model for community consultation.

The study was carried out following population genetic studies of heritable susceptibility to Canavan's disease and to breast cancer (from inheritance of the BRCA2 6174delT mutation) among Ashkenazi Jews ${ }^{4,5}$. The participants in these studies were Ashkenazi Jewish people who had sought carrier testing for Tay-Sachs disease and cystic fibrosis. Approval of the institutional review board was obtained and subjects provided specific consent for anonymous population genetic studies of heritable susceptibility to these conditions. Samples were rendered anonymous upon receipt in the laboratory so that they could no longer be linked to their identifiers.

The results of the BRCA2 study received widespread coverage in the press and on television. Results of this study were presented at national scientific meetings and at leadership meetings of Jewish organizations. Letters about heritable susceptibility to disease among Jews were sent to synagogues and Jewish community centres. In the face of all this publicity, individuals have continued to provide their consent for such analyses both before and after the colon cancer study, and 1,600 DNA samples have been accumulated. Indeed, as the director of the genetic screening programme and the population genetic registry upon which these studies were based, I can assume only that the participants who spoke to physicians and counsellors in my programme and provided informed consent were acting as representatives of their community.

The intention of these studies was to benefit rather than create mischief for the Ashkenazi Jewish community. Because the colon cancer study was based on a relatively small sample and because of concern about unfair genetic discrimination, I expressed caution about lowering the threshold for offering genetic testing until the risks of being a carrier were more precisely quantified $^{6}$. On the other hand, carrier screening for Canavan's disease has become standard. The usefulness and limitations of heterozygote testing for $B R C A 2$, along with $B R C A 1$, have been validated in a series of other studies for people with a family history of breast cancer.

Throughout this time, serving the needs and maintaining the trust of the Ashkenazi Jewish community have been the paramount concerns of my programme. Harry Ostrer

Human Genetics Program, NYU Medical Center,

550 First Avenue, MSB 136,

New York, New York 10016, USA

e-mail:ostreh01@mcrcr6.med.nyu.edu

Sir - I read with interest and dismay the News article about the recommendations on informed consent and the ethical use of tissue samples to be issued by the US National Bioethics Advisory Commission ${ }^{2}$.

There is no doubt that the use of archival tissues for genetic epidemiological and pathological studies carries with it complicated ethical issues - for example, who should profit from the discoveries made using this material? One of the arguments put forward to restrict scientific access to these samples, however, is that the information creates job and insurance risks for the individuals or populations analysed. Clearly, job and insurance discrimination are potential dangers associated with this type of research and there are many reasons to argue that these should be avoided.

However, the approach of restricting scientific access to archived tissue samples is not the way to do it. In many ways this is like saying that we should prevent stores from selling sharp knives because they might be used to harm someone. Knives can be very useful or very dangerous, depending on the use. The

recommendations and legislation should be aimed not at the scientists, but at the uses that we consider unethical. Many of us believe that insurance discrimination is one such area. Perhaps our efforts would be better spent considering the ethics of the insurance practices that will be affected by the new information.

Most scientists are using these archived samples to investigate disease pathogenesis. This knowledge can be used to develop better diagnostic and treatment strategies to help the individuals and populations afflicted by the disease. Indeed, the populations affected have the most to gain from the scientific use of their specimens.

The bottom line is that the scientific use of archived samples is good for all of society. This fact will not change no matter how many different communities are consulted. If this is considered unethical, maybe we should re-examine our ethics rather than hinder the progress of biomedical research.

\section{Richard H. Scheuermann}

\section{Louis J. Picker}

Department of Pathology,

University of Texas, Southwestern Medical Center,

Dallas, Texas 75235-9072, USA

e-mail:scheuermann.richard@

pathology.swmed.edu

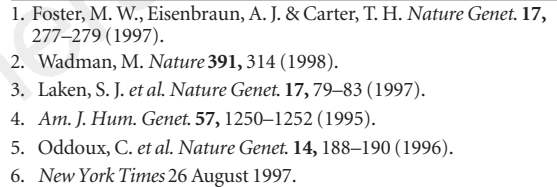

\section{About face}

Sir - Although I am grateful that my book About Face was reviewed in Nature (390, 458 ; 1997), I should like to point out that, contrary to Stuart Sutherland's claim, I was not instrumental in setting up the charity Changing Faces.

Sutherland also says that I suggest that the emotional problems in autism stem from an inability to interpret others' facial expressions. I find it difficult to see how he arrives at this simplistic conclusion. In the book I write: "But autism, of course, is a widespread developmental disorder, not just a face thing. Do the many other problems [autistic people] have preclude too many conclusions about relatedness and social development based on facial action? Perhaps. But what if there were people with facial problems alone, and what if they experienced some similar difficulties in relatedness? Autism is a condition with problems in social interaction which are reflected in their problems with the face. What if we could turn this upside down? How might facial problems affect social development and selfhood?"

Although coming at the end of the chapter on autism, these questions are used as a bridge to refer to the next chapter on Möbius syndrome (in which people have congenital lack of facial movement). Sutherland seems to have missed this link.

Indeed, I write later: "Autism of course is not a face problem in the way Möbius Syndrome is".

Jonathan Cole

Hollyhock Cottage, Minstead,

Lyndhurst,

Hampshire SO43 7GG, UK

e-mail:jcole@minstead.demon.co.uk 